\title{
Construcción de carreras políticas a nivel subnacional: un análisis comparativo de las provincias de Yungay y Satipo ${ }^{+}$
}

\author{
JULIO ENRIQUE GUTIÉRREZ VERA* \\ Pontificia Universidad Católica del Perú \\ julio.gutierrezv@pucp.pe \\ https://doi.org/10.18800/rcpg.201602.007
}

\section{RESUMEN}

El presente trabajo se propone evidenciar una característica actual de la política subnacional en el Perú: personas que se encuentran construyendo carreras políticas desde hace varios años y dominan la oferta política local. En ese sentido, la investigación desarrolla un indicador sobre carreras políticas a nivel nacional que se construye a partir del analisis del pasado político de los candidatos a las alcaldías provinciales de los tres últimos procesos electorales. Finalmente, y desde un análisis comparado de las provincias de Yungay y Satipo, la investigación plantea tres variables independientes: 1) la presencia de instituciones educativas como espacios de socialización política, 2) los rezagos del sistema de partidos de la década de 1980 y 3) la apertura política a los migrantes, para explicar los factores que han permitido la construcción de carreras políticas a nivel subnacional.

Palabras clave: carreras políticas, ambición política, política subnacional, volatilidad, partidos políticos.

Construction of political careers at the subnational level: a comparative analysis of the provinces of Yungay and Satipo

\footnotetext{
Abstract

This paper aims to highlight the presence of a current characteristic of the subnational politics in Peru, which is that the people who are dominating the local political offer are the ones who are constructing their political careers for several years. In that sense, the research develops an indicator on political careers that was constructed from the analysis of the candidate's political past to the provincial mayors of the last three electoral processes. Finally, the comparative analysis of Yungay and Satipo provinces provides allows the research to pose three independent variables: 1) The presence of educational institutions as spaces of political socialization, 2) The lags of the party system of the eighties and 3) The political openness to the migrants, to explain the factors that have allowed the construction of political careers at the subnational level.

Key words: political careers, political ambition, subnational politics, volatility, political parties.

* Licenciado en Ciencia Política y Gobierno por la Pontificia Universidad Católica del Perú (PUCP). Miembro del Grupo de Investigación de Política Subnacional (GIPSN-PUCP).

+ Recibido el 25 de enero de 2017; aceptado el 6 de marzo de 2017.
} 



\section{INTRODUCCIÓN}

El domingo 5 de octubre de 2014 se llevaron a cabo las elecciones municipales y regionales en todo el Perú y se eligieron 25 presidentes regionales, 195 alcaldes provinciales y 1643 alcaldes distritales.

El profesor Enrique Chávez Vara tentaba por segunda vez el sillón municipal de la provincia de Yungay; anteriormente había sido candidato para la alcaldía en 2010 y probó suerte al cargo de regidor municipal de Yungay en 2006 y 1998. Para esta contienda electoral tuvo como principales contendores al exalcalde de 2010, Juan Cuellar Broncano; al exalcalde de 2006, Cico Fernando Alamo Figueroa; al exalcalde distrital de Mancos en el periodo 2010, Avelino Huacanca Chuccho; quienes ocuparon el segundo, tercer y cuarto puesto, respectivamente. También tuvo como rivales al exalcalde provincial de 1995, Fortunato Vidal Méndez Melgarejo; al consejero regional de 2002, Marcos Flores Dolores; a la consejera regional de 2010, Magdalena Gamarra Cruz; y a un outsider en la política local, Hugo Baylón Rojas. Finalizadas las elecciones, el profesor Chávez lograría ganar la alcaldía provincial, imponiéndose a candidatos con experiencia política y reconocidos en la localidad.

Como podemos observar, este proceso electoral en la ciudad de Yungay presenta a siete candidatos con una carrera política constituida y cuya ambición política se ha mantenido constante. Este fenómeno no es particular de la provincia de Yungay, por el contrario, es una situación constante en la mayoría de provincias del Perú. Por ejemplo, para las elecciones locales de 2014 hubo un promedio de $74 \%$ de candidatos que tenían experiencia política dentro de la oferta electoral de cada provincia. Esto quiere decir que, aproximadamente, siete de cada diez candidatos han venido construyendo carrera política en sus localidades, lo que demuestra que si bien tenemos cifras altas de volatilidad partidaria, esta puede ser distinta cuando se observa a los candidatos.

En ese sentido, el artículo se plantea responder a la siguiente interrogante: ¿qué factores han permitido la construcción de carreras políticas a nivel subnacional en el Perú?, mediante el estudio de casos de manera comparada. Para la selección de los casos de estudio se realizó un indicador sobre los niveles de construcción de carreras políticas en todas las provincias del país. Este comprendió un análisis sobre el pasado polìtico de cada uno de los postulantes a las alcaldías provinciales durante los tres últimos procesos electorales. De esta forma, se seleccionó a las provincias de Satipo y Yungay, ambas localidades de características similares pero con resultados distintos. 
Esta respuesta nos mostrará las condiciones que han surgido a nivel subnacional para que exista un número mayor o menor de políticos que han construido carreras políticas y que se mantienen en el espectro político local constantemente.

Este análisis es importante para saber cómo funciona la política a nivel local y cómo se están construyendo carreras políticas, en un contexto donde los partidos no logran tener éxito en elecciones subnacionales y las organizaciones locales y regionales, en su mayoría, son efímeras (no pueden sobrevivir más de una elección). Damos cuenta que en la política subnacional peruana los que persisten son los líderes políticos, personas que están construyendo carreras políticas, de distintas formas, y que probablemente articulan más intereses de la sociedad que los propios partidos.

\section{CARRERAS POLÍTICAS Y VOLATILIDAD ELECTORAL}

\section{Estudios sobre volatilidad electoral en el Perú}

Recientemente, Aragón e Incio discuten algunas de las mediciones sobre volatilidad en el país y se basan en algunos de los conceptos generales de Pedersen (1979), que decía que un «sistema de partidos electoral puede ser descrito a partir del número de partidos que compiten en una elección y la distribución del apoyo electoral entre esos partidos. Por ello plantea la volatilidad electoral como herramienta de medición para observar los cambios en el sistema de partidos» (Aragón e Incio, 2015, p. 3).

Para la volatilidad electoral a nivel subnacional en el Perú, mucho del sentido común de las personas podría indicarnos que dado que entre una y otra elección cada vez se presentan un número mayor de organizaciones políticas, la volatilidad podría ser más alta. Como podemos observar en la Tabla 1, el crecimiento en número de listas que postulan al cargo de gobernación regional ha ido en aumento, sobre todo si observamos las elecciones de 2006 y 2010, cuyo crecimiento ha sido mayor. Actualmente, en cada región hay entre once y trece candidatos regionales que buscan llegar a la gobernación regional.

Asimismo, si observamos la tasa de reelección en autoridades regionales (Gráfico 1), veremos que esta tendencia se encuentra en disminución, además de ser muy baja. 
Tabla 1. Elecciones 2002, 2006, 2010 y 2014

\begin{tabular}{|l|c|c|c|c|}
\hline \multicolumn{1}{|c|}{} & Elecciones 2002 & Elecciones 2006 & Elecciones 2010 & Elecciones 2014 \\
\hline Total de organizaciones & 223 & 225 & 295 & 306 \\
\hline Promedio & 8,92 & 9 & 11,8 & 12,24 \\
\hline
\end{tabular}

Fuente: JNE-Infogob. Elaboración propia.

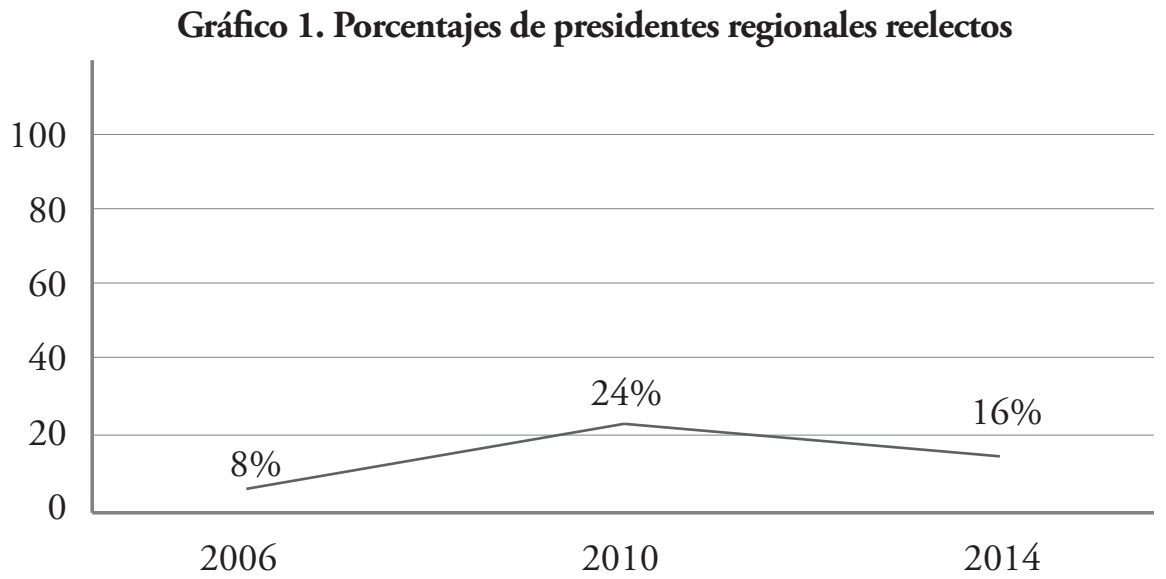

Fuente: JNE-Infogob. Elaboración propia.

Por ello, si observamos de manera conjunta estos dos factores, aumento de organizaciones en las elecciones y las bajas tasas de reelección, se puede esperar que el Perú sea un país con una tasa de volatilidad alta, donde las personas están optando por opciones diferentes entre una oferta que se hace cada vez más grande.

Siguiendo esta línea, Vera (2010) y Barrenechea (2010) realizan aproximaciones al cálculo de volatilidad electoral en las regiones del Perú en las elecciones de 2006 y 2010. Vera obtiene como resultados que: «En promedio, la volatilidad de las regiones alcanza el 41,2\% para el periodo 2002-2006 y el $39,8 \%$ para el periodo 2006-2010» (Vera, 2010); por lo que se puede observar que ha venido disminuyendo durante estos tres procesos, y además se resalta la heterogeneidad de los resultados; lo que lleva a que la autora asuma que existen lugares donde si bien se están consolidando liderazgos regionales, también existen algunas organizaciones políticas que están perseverando y recuperan su nivel de votación en cada elección (Vera, 2010). 
Por su parte, Barrenechea realiza un trabajo similar al de Vera para medir la volatilidad en las regiones y considera que esta se ha reducido drásticamente; además propone algunas cuestiones importantes:

[...] la volatilidad se reduce pese al aumento significativo en el número de candidaturas a nivel regional, es porque el electorado en estas circunscripciones comienza a discernir entre lo que inicialmente fue un conjunto indistinguible de candidatos. Los bandazos electorales se han reducido en tamaño. Con los años, algunos liderazgos van resaltando, malos gestores se van desinflando y los electores les renuevan su confianza a los exitosos (Barrenechea, 2010).

Como podemos observar, si bien ambos autores demuestran evidencia sobre la reducción en volatilidad electoral a nivel subnacional en el Perú, estos cálculos se basan en el seguimiento a la volatilidad de los partidos o movimientos políticos elección tras elección. Sin embargo, considero que observar los cálculos de volatilidad analizando a los políticos de manera independiente a los resultados de los partidos podría dar mayores luces de esta reducción.

\section{Las carreras políticas como un indicador de volatilidad}

La literatura sobre el funcionamiento de la política subnacional en el Perú ha resaltado la existencia de liderazgos políticos que vienen dominando la escena local, personas cuyo calificativo de líderes tiene como una de sus características la construcción de una carrera política mediante la persistencia de participaciones en los procesos electorales.

Para identificar cómo es la situación de las carreras políticas en el Perú, se diseñó un indicador a nivel provincial que analiza el pasado de los políticos. Se eligió realizar el estudio a nivel provincial, ya que esta dimensión es un espacio medio entre todos los cargos a los que puede participar un político, considerando el cargo de nivel distrital como el inicio de la carrera política y los cargos a nivel nacional como los últimos que aspira ocupar un político.

Para ello, lo primero que se realizó fue la construcción de una base de datos para las tres últimas elecciones municipales y regionales, 2006, 2010 y 2014 , que consistió en el análisis del pasado político de todos los candidatos de los partidos o movimientos que postulaban al cargo de alcaldía de cada provincia. Por ejemplo, en la provincia de Chincha en el año 2006 podemos observar que el $46 \%$ de postulantes han tenido experiencia política previa en postulaciones a distintos cargos $(1=S \mathrm{I}, 0=\mathrm{NO})$. Por postulante con experiencia política previa entendemos a un candidato que ha postulado por lo menos una vez a cualquier cargo de elección como congresista, presidente regional, consejero regional, alcalde provincial, alcalde distrital, regidor, etcétera. 
Tabla 2. Candidatos a la alcaldía provincial para las elecciones 2006

\begin{tabular}{|c|c|c|c|c|c|c|}
\hline Región & Provincia & $\begin{array}{c}\text { Ap. } \\
\text { paterno }\end{array}$ & $\begin{array}{c}\text { Ap. } \\
\text { materno }\end{array}$ & Nombre & $\begin{array}{c}\text { Postuló antes } \\
(\text { Sí=1 / No=0 })\end{array}$ & $\begin{array}{c}\text { Número de } \\
\text { postulaciones }\end{array}$ \\
\hline Ica & Chincha & Navarro & Grau & José Alberto & 1 & 8 \\
\hline Ica & Chincha & Sánchez & Acevedo & Juan Pedro & 1 & 4 \\
\hline Ica & Chincha & Girao & Oliva & José Alejandro & 0 & - \\
\hline Ica & Chincha & Amoretti & Mendoza & Félix Juan & 1 & 6 \\
\hline Ica & Chincha & Chumbiau & Delgadillo & Eusebio Alejandro & 1 & 1 \\
\hline Ica & Chincha & Tasso & Monticelli & Eudosia Giuseppina & 0 & - \\
\hline Ica & Chincha & Grimaldi & Moyano & Carlos Alberto & 1 & 1 \\
\hline Ica & Chincha & Yong & Meza & Alfonso Santiago & 1 & 2 \\
\hline Ica & Chincha & Pacheco & Huamán & Ricardo & 0 & - \\
\hline Ica & Chincha & Jordán & Navarro & Gonzalo & 0 & - \\
\hline Ica & Chincha & Franco & Reátegui & María Elizabeth & 0 & - \\
\hline Ica & Chincha & Uribe & Gómez & Luis Alfredo & 0 & - \\
\hline Ica & Chincha & Higaki & Silva & Omar Alejandro & 0 & - \\
\hline
\end{tabular}

Fuente: JNE-Infogob. Elaboración propia.

El mismo proceso se realizó para el año 2010, donde el 100\% de participantes a la elección tenía experiencia previa en procesos electorales.

Tabla 3. Candidatos a la alcaldía provincial para las elecciones 2010

\begin{tabular}{|c|c|c|c|c|c|c|}
\hline Región & Provincia & $\begin{array}{c}\text { Ap. } \\
\text { paterno }\end{array}$ & $\begin{array}{c}\text { Ap. } \\
\text { materno }\end{array}$ & Nombre & $\begin{array}{c}\text { Postuló antes } \\
(\text { Sí=1/ No=0 })\end{array}$ & $\begin{array}{c}\text { Número de } \\
\text { postulaciones }\end{array}$ \\
\hline Ica & Chincha & Veliz & Flores & Manuel & 1 & 5 \\
\hline Ica & Chincha & Del Solar & Celis & Benjamín Grimaldi & 1 & 2 \\
\hline Ica & Chincha & Amoretti & Mendoza & Félix Juan & 1 & 7 \\
\hline Ica & Chincha & Juárez & Ochoa & Lucio & 1 & 5 \\
\hline Ica & Chincha & Sánchez & Acevedo & Juan Pedro & 1 & 5 \\
\hline Ica & Chincha & Navarro & Grau & José Alberto & 1 & 9 \\
\hline Ica & Chincha & Ore & Quispe & Miguel Ángel & 1 & 2 \\
\hline Ica & Chincha & Apolaya & Munares & Juan Germán & 1 & 1 \\
\hline Ica & Chincha & Chumbiauc & Delgadillo & Eusebio Alejandro & 1 & 2 \\
\hline Ica & Chincha & Girao & Oliva & José Alejandro & 1 & 1 \\
\hline
\end{tabular}

Fuente: JNE-Infogob. Elaboración propia. 
Finalmente, para 2014 se observa que en la misma provincia se presentaron un total de doce candidatos, de los cuales diez tenían experiencia previa, lo que significó un $83,3 \%$ del total.

Tabla 4. Candidatos a la alcaldía provincial para las elecciones 2014

\begin{tabular}{|c|c|c|c|c|c|c|}
\hline Región & Provincia & $\begin{array}{c}\text { Ap. } \\
\text { paterno }\end{array}$ & $\begin{array}{c}\text { Ap. } \\
\text { materno }\end{array}$ & Nombre & $\begin{array}{c}\text { Postuló antes } \\
(\text { Sí=1 / No=0 })\end{array}$ & $\begin{array}{c}\text { Número de } \\
\text { postulaciones }\end{array}$ \\
\hline Ica & Chincha & Rojas & Vásquez & Leandro Víctor & 1 & 2 \\
\hline Ica & Chincha & Grimaldi & Moyano & Carlos Alberto & 1 & 4 \\
\hline Ica & Chincha & Donola & Ortega & Pía Del Rosario & 1 & 1 \\
\hline Ica & Chincha & Luyo & Del Risco & Martín Jesús & 1 & 2 \\
\hline Ica & Chincha & Sánchez & Acevedo & Juan Pedro & 1 & 6 \\
\hline Ica & Chincha & Huamán & Tasayco & Armando & 1 & 2 \\
\hline Ica & Chincha & Wong & Chávez & Romualdo César & 0 & - \\
\hline Ica & Chincha & Mendieta & Leyva & Alfredo Teobaldo & 0 & 2 \\
\hline Ica & Chincha & Giorffino & Coloritti & Mario Agustín & 1 & 10 \\
\hline Ica & Chincha & Navarro & Grau & José Alberto & 1 & 6 \\
\hline Ica & Chincha & Velit & Flores & Manuel & 1 & 1 \\
\hline Ica & Chincha & Carranza & Falla & César Antonio & 1 & 2 \\
\hline
\end{tabular}

Fuente: JNE-Infogob. Elaboración propia.

De esta forma, se realizó una base de datos para las 194 provincias del país, no se tomó en cuenta el caso de Lima Metropolitana, ya que esta provincia, por su condición de capital del país, cuenta con características sociodemográficas distintas al resto de provincias.

La segunda parte del cálculo del indicador consistió en realizar un cálculo porcentual de los resultados de los tres procesos electorales (2006, $2010 \mathrm{y}$ 2014) de cada provincia a fin de poder presentar un indicador de los lugares donde existe una mayor cantidad de personas que construyen carreras políticas y observar los casos donde ocurre lo contrario.

Siguiendo el ejemplo de la provincia de Chincha, obtenemos que el promedio es $76 \%$, este es un primer indicador para generar clasificaciones, como se explicará líneas abajo. 
Tabla 5. Promedio resultados 2006, 2010 y 2014

\begin{tabular}{|c|c|c|c|c|c|}
\hline Región & Provincia & Res. 2006 & Res. 2010 & Res. 2014 & Promedio \\
\hline Ica & Chincha & $46 \%$ & $100 \%$ & $83 \%$ & $76 \%$ \\
\hline
\end{tabular}

Fuente: JNE-Infogob. Elaboración propia.

Este proceso puede ser mejor observado en el mapa provincial (Gráfico 2), donde se realizó una división en deciles de los promedios, obteniendo los siguientes resultados.

Gráfico 2. Indicador de construcción de carreras políticas a nivel provincial

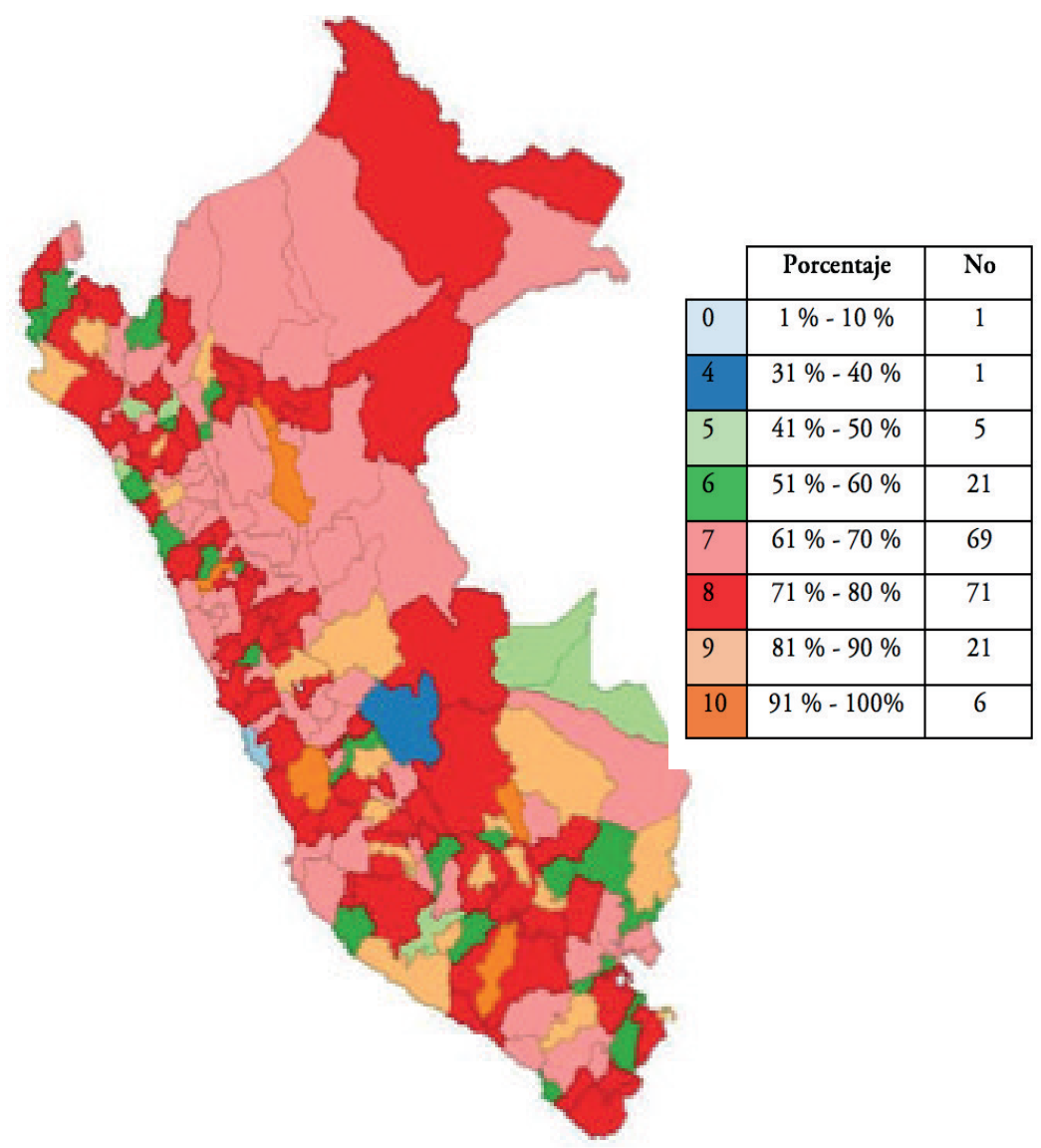

Fuente: JNE-Infogob. Elaboración propia. 
En ese sentido, observamos que en el Perú la gran mayoría de provincias cuenta con una media entre $60 \%-80 \%$, lo que evidencia que, por lo menos, de diez candidatos a la alcaldía municipal, entre seis a ocho son personas que vienen desarrollando una carrera política en su localidad, y muchos de ellos han sido alcaldes provinciales, congresistas, consejeros regionales, alcaldes distritales o regidores; o han estado tentando estos puestos constantemente. Esta evidencia, además, nos conecta directamente con lo descrito anteriormente sobre volatilidad electoral, ya que si bien la propuesta no observa la volatilidad de los partidos elección tras elección, lo que sí plantea es observar el cambio de preferencias de los votantes de una elección a otra, donde podemos observar que si bien esto puede o no haberse mantenido estable, lo que ha cambiado poco es la oferta de políticos en las provincias. En ese sentido, esto también hace referencia del poco éxito que puede estar teniendo un político nuevo u outsider en un proceso electoral, ya que se evidencia que los ciudadanos prefieren votar por algún político que haya tenido experiencia de gestión o que, por lo menos, su campańa política venga siendo trabajada desde antes, y no solo para la presente elección.

Pero así como existen estos casos, también existen casos donde el resultado del indicador está por debajo de la media, espacios donde la puerta a la política es más accesible al outsider, por lo que sus posibilidades de ocupar la alcaldía provincial también se verán crecientes, ya que existe un número reducido de candidatos con carreras políticas constantes.

De esta forma, cabe preguntarnos ¿qué factores han surgido, o no han surgido, en estas provincias para que la dinámica política tenga esas particularidades, en contraste a otras provincias?

En ese sentido, el siguiente capítulo realizará un estudio de análisis comparado, para lo cual se seleccionó dos casos opuestos, uno donde existe una mayor presencia de candidatos con carreras políticas y otro donde existen pocos políticos con carreras.

El primer caso seleccionado es la provincia de Satipo, ubicada en la región Junín, que obtuvo un $40 \%$ en promedio para los tres procesos electorales, siendo el promedio más bajo de todas las provincias. Mientras que el caso opuesto es la provincia de Yungay, en la región Áncash, que durante los tres procesos electorales obtuvo un promedio de $93 \%$, siendo el cuarto caso de promedio más alto.

El estudio de estos casos se realizó mediante un conjunto de entrevistas semiestructuradas dirigidas a dos tipos de candidatos: aquellos políticos que tenían experiencia previa y aquellos que solo han postulado una vez; información 
que se obtuvo observando la lista de postulantes y el pasado político de cada uno para las elecciones de 2002, 2006, 2010 y 2014.

Asimismo, se realizaron entrevistas a regidores, periodistas, dirigentes políticos y personajes notables de la ciudad. A estas fuentes primarias de información se sumó un análisis continuo de los resultados electorales en ambas provincias; así como el uso de fuentes secundarias que se lograron articular en tres variables independientes como respuesta a nuestra pregunta de investigación.

\section{Análisis comparado de los casos: Yungay y Satipo}

Como hemos señalado previamente, el estudio de casos de manera comparada buscó encontrar respuestas a nuestro fenómeno a partir de observar dos casos opuestos. En ese sentido, se plantean tres hipótesis relacionadas a los procesos de socialización política de las personas. Este concepto hace referencia a aquellos espacios formativos donde un individuo podrá desarrollar sus concepciones sobre política y, además, se desarrollará políticamente. Según Henry Pratt (1984), la socialización política es un proceso sociopsicológico por el cual se forma la personalidad bajo el influjo de instituciones. Estos procesos han sido definidos en dos etapas de acuerdo a la edad cronológica: la socialización política primaria y la socialización política secundaria, donde los agentes que la forman son distintos.

Según Pereira:

Los agentes secundarios de socialización política, son usualmente los siguientes: los grupos de pares (amigos, compańeros), las instituciones educativas, los medios de comunicación, las organizaciones religiosas, las variadas instituciones civiles incluidos los sindicatos y las instituciones políticas, entre las cuales son fundamentales los partidos políticos (Pereira, 1992, p. 36).

En la presente investigación se plantea como variables explicativas a dos agentes que corresponden a los procesos de socialización política secundaria, las instituciones educativas y los partidos políticos, siendo fundalmente su análisis desde esta perspectiva para entender los procesos de construcción de carreras políticas. Finalmente, se plantea una tercera variable sobre las variables socioculturales de cada provincia y su influencia en la política local.

\section{Instituciones formativas y la socialización política}

Las instituciones educativas son espacios de formación profesional, pero a la vez de socialización política, ya que forman una masa crítica que puede tener injerencia social y política sobre el manejo político y económico de su localidad. 


\section{Yungay y el Pedagógico}

El Instituto Superior de Educación Pública Ignacio Amadeo Ramos Olivera (ISEP IARO) de la ciudad de Yungay fue fundado en 1930. En una primera instancia, como Escuela Normal de Formación Pedagógica, imparte las carreras de Educación Inicial y Primaria, Educación Física y algunas carreras técnicas; actualmente no imparte la carrera de Educación Secundaria, pero anteriormente lo hizo con las siguientes especialidades: Matemática, Lengua y Literatura, Matemática y Física, Biología y Química, Historia y Geografía, Filosofía y Ciencias Sociales, Educación Física y Agropecuaria.

El alto grado de influencia que ha tenido el ISEP IARO en el desarrollo de la provincia de Yungay se ha dado, básicamente, por la monopolización de la oferta educativa superior en la provincia, creando una especie de transición circular en la educación donde los profesionales egresados son los mismos que enseñan en los colegios de la provincia y muchos de los jóvenes que egresan de los colegios terminan estudiando en el Pedagógico (nombre usado por los pobladores de Yungay para referirse al ISEP IARO).

En ese sentido, este espacio de socialización dentro de la provincia es también un espacio de socialización política. Si observamos el Gráfico 3, podemos ver que en un universo de diecinueve postulantes a la alcaldía de la provincia durante las tres últimas elecciones, el $47 \%$ tiene un vínculo laboral o formativo con el Pedagógico; mientras que un 37\% ha realizado estudios superiores en otras instituciones de la región y del país, y, finalmente, hay un 16\% que no ha tenido formación superior.

\section{Gráfico 3. Políticos de Yungay según institución educativa}

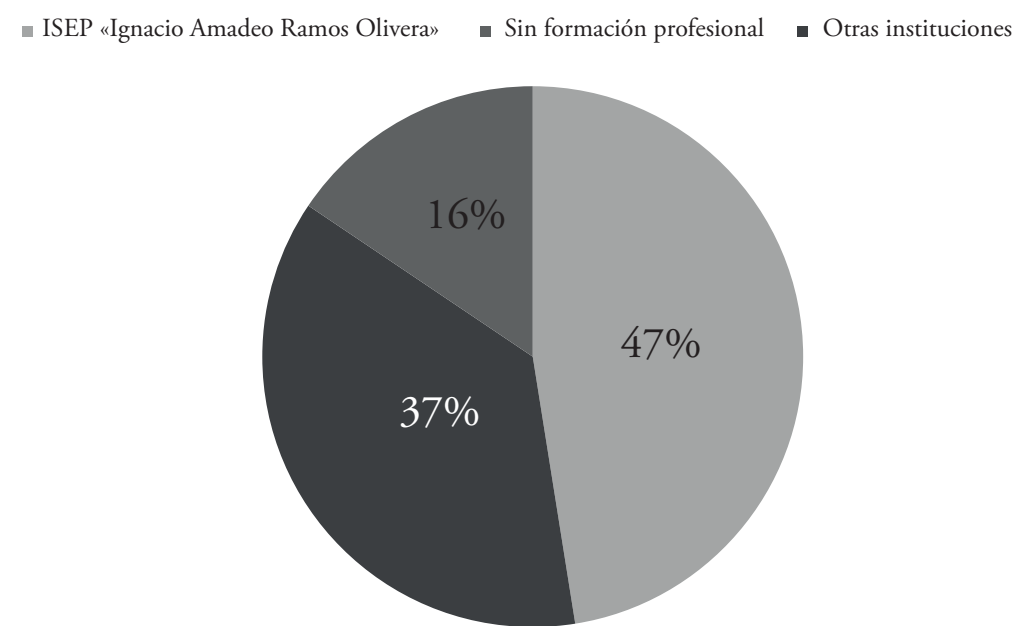

Fuente: JNE-Infogob. Elaboración propia. 
Siguiendo esta línea, podemos afirmar que una gran parte de los políticos de la provincia de Yungay han estudiado y/o laboran en el instituto, lo que nos lleva a hablar de un espacio de socialización política que no solo influye en la votación, sino que también es un generador de políticos y futuros gobernantes de la provincia, ya que el Pedagógico, como varias instituciones de educación superior públicas, cuenta con espacios de desarrollo político interno como la Federación de Estudiantes, el Sindicato de Profesores, el Sindicato de Trabajadores, entre otros espacios donde algunos de los políticos yungaínos inician su carrera política para después pasar a niveles de representación en los distritos y provincias.

\section{Satipo}

En la provincia de Satipo - recordemos que este es el caso de baja cantidad de políticos que tienen carreras políticas - no existe una institución de formación superior que pueda ser comparada con la monopolización educativa del Pedagógico. La educación superior en Satipo se ha venido desarrollando en dos campos. Por un lado, existen las sedes de instituciones superiores privadas, como la Universidad Privada Los Andes de Huancayo, que cuenta con una sede en Satipo para las carreras de Administración y Derecho. Esta oferta de instituciones privadas es reciente y ha venido en aumento con la presencia de instituciones de la ciudad de Huancayo, Huánuco y Lima que ofrecen programas a distancia para formación profesional.

Por otro lado, en el distrito de Mazamari se encuentra la Escuela Superior Técnica PNP, esta cuenta con una tradición de varios años en la ciudad, pero debido a su naturaleza de formación policial, el espacio de socialización política que ofrece es limitado, sin dar oportunidad a los alumnos y egresados de ser partícipes directos de la política.

Como podemos ver en el Gráfico 4, la formación profesional de los políticos en Satipo ha sido bastante variada. La única institución que cuenta con más de dos políticos provenientes de sus aulas es la Universidad Nacional del Centro del Perú, cuya sede principal se ubica en la provincia de Huancayo, a ocho horas, en promedio, de la ciudad de Satipo. Asimismo, observamos que la gran mayoría de políticos proviene de distintas instituciones, casi todas situadas en otras regiones del país. Además encontramos a un pequeño grupo de políticos que no cuenta con formación profesional. 


\section{Gráfico 4. Políticos de Satipo según institución educativa}

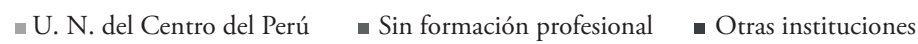

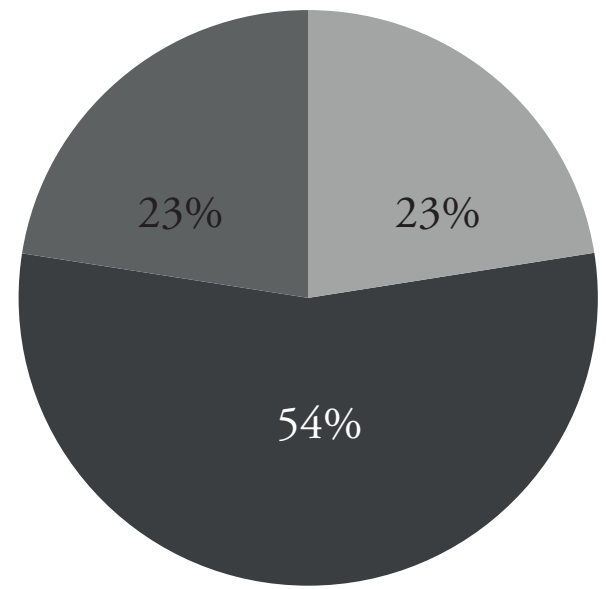

Fuente: JNE-Infogob. Elaboración propia.

Finalmente, podemos afirmar que la formación profesional de los políticos en ambas provincias se da en instituciones con características distintas. Por ello, resalta la presencia del Pedagógico de Yungay en la política de la ciudad, como una institución local monopolizadora de la educación superior y de espacios de socialización política por muchos años; mientras que en Satipo no existe una institución educativa comparable y que tenga la capacidad de influir tanto en la política de la provincia.

Rezagos del pasado, lo que quedó de los partidos políticos de la década de 1980 La literatura de la ciencia política sobre el Perú reconoce la existencia de un sistema de partidos políticos representativo que se dio en el país a fines de la década de 1970 e inicios de la de 1980, con la presencia de partidos como el APRA y la Izquierda Unida, anteriormente censurados, que se sumaban a la participación de Acción Popular y el Partido Popular Cristiano, que cumplían algunos requisitos mínimos para encuadrar las preferencias de los ciudadanos (Tanaka, 1998). Pero este sistema de partidos políticos tuvo una corta duración, ya que con las reformas políticas del gobierno de Fujimori, este se vio desmoronado.

En los niveles locales, este sistema de partidos políticos funcionó de la misma forma que a nivel nacional. Las autoridades, en su mayoría, eran representantes de alguno de los cuatro partidos predominantes y existían, en cierta medida, 
bases y formación partidaria en cada provincia. Tras la caída del sistema de partidos, toda esta estructura formada por los partidos se vio debilitada y se fue desmoronando, dando paso a un nuevo sistema de partidos.

Actualmente tres de los partidos continúan con su participación política, mientras que el movimiento de Izquierda Unida se vio disuelto y muchos de sus militantes terminaron dispersos en varios movimientos de la misma línea ideológica pero sin mayor representatividad.

Este desmoronamiento del sistema de partidos generó tres efectos respecto a los militantes. Primero, tendremos a los militantes que se desvincularon totalmente de la política y, por la tanto, de sus partidos. Segundo, contamos con los militantes que siguieron haciendo política pero en otros partidos o movimientos que les ofrecieron mejores incentivos para lograr sus metas políticas. Tercero, tenemos a los militantes que se han mantenido leales a sus partidos y que siguen participando en las actividades de los mismos.

En la actualidad, algunos de los políticos que han construido carreras políticas en las provincias han sido militantes de los partidos políticos en la década de 1980 y continúan participando en política, ya sea leales a su partido de origen o con nuevos movimientos regionales, como lo demuestra Vilca (2014) para el caso de Puno.

A continuación, observaremos el desempeño de estos cuatro partidos en las provincias de Yungay y Satipo durante las elecciones a la alcaldía municipal en 1980, 1983, 1986, 1989 y 1993. Estos resultados nos brindan un esbozo de qué tan arraigados estuvieron los partidos en estas ciudades y cómo sus militantes participan ahora en la política local.

\section{El Partido Aprista Peruano (PAP)}

El PAP, quizás el partido político más importante del Perú, ha tenido un buen desempeño en ambas ciudades, pero debemos resaltar que este ha sido mejor en Yungay, teniendo una media de 39\%; mientras que en Satipo el APRA obtiene una media de $22 \%$, lo que hace referencia a que el PAP, además de haber tenido mejores resultados en Yungay, ha tenido un mejor enraizamiento ahí que en Satipo, lo cual también se ve reflejado al dialogar con algunos de los políticos locales que reconocen su afiliación partidaria. 


\section{Gráfico 5. Resultados electorales (1980-1993) para el PAP}

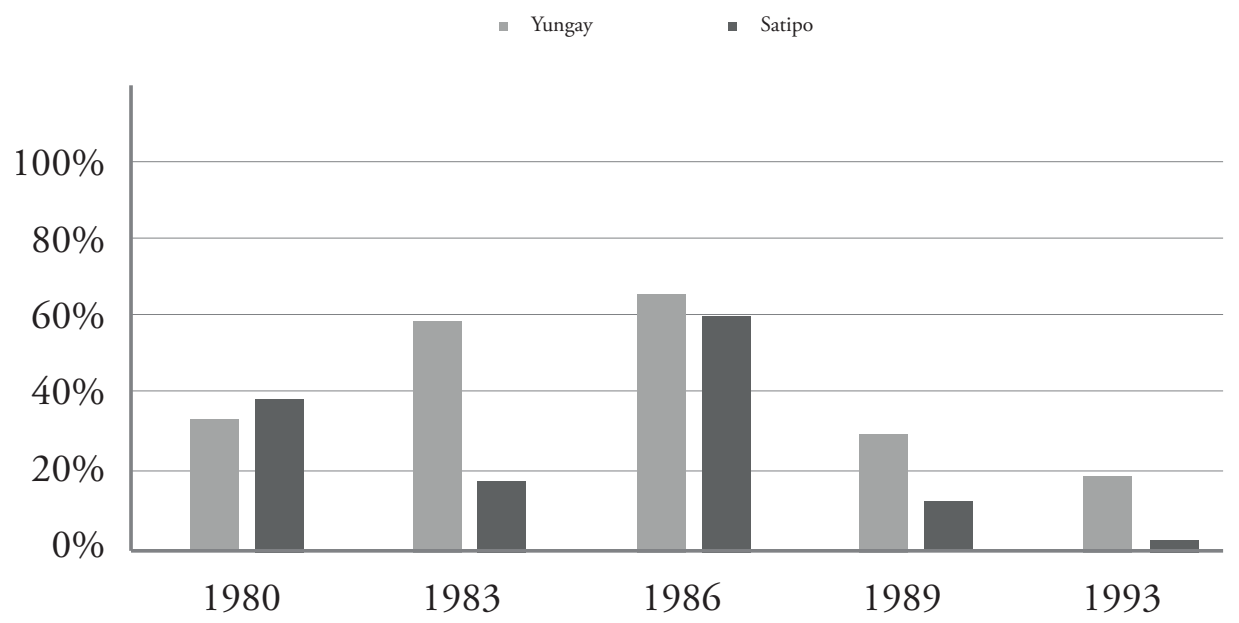

Fuente: JNE-Infogob. Elaboración propia.

Ahora bien, este desempeño positivo del APRA duró hasta 1993, después, y junto al desmoronamiento del sistema de partidos, el partido ya no obtuvo resultados tan favorables. De las siguientes seis elecciones, solo participó en la mitad de ellas (1998, 2002 y 2006), obteniendo resultados menores al 10\%. Sin embargo, la formación partidaria de sus militantes ha sido importante para la construcción de las carreras de algunos políticos de la ciudad, que si bien no han participado con la marca partidaria aprista, sí reconocen su labor, como es el caso de Segundo Jacome, antiguo militante aprista que se desvinculó del partido tras la elección de 2002.

Yo he sido aprista desde mis padres, ellos me han ido formando como parte del PAP, bajo la ideología de Haya de la Torre [...] para las elecciones a la consejería regional en el 2002 yo fui voceado como candidato en el puesto número 7, entonces tenía opción de que si ganaba el partido, yo entraba a la consejería, pero faltando pocos minutos a mí me pusieron en el puesto número 13 y para mí fue una experiencia desagradable; no pensé que en el APRA se manejaban las cosas de esa forma (S. Jacome, comunicación personal, 07 de agosto de 2015).

Estos malos manejos y disputas internas hicieron que otro político, Cico Alamo, tres veces exalcalde con el APRA en la provincia, se desligue del partido, y que un grupo de apristas siguiera su camino político en otros movimientos locales. De la misma forma, podemos observar a Froilan Cusi, un excandidato relegado en el APRA para los procesos locales, que empezó a postular con otras listas. 


\section{Acción Popular}

Para 1980, el partido Acción Popular (AP) había logrado por segunda vez la presidencia de la República. El trajín de los años previos a la campaña llevó a que su presencia y aceptación fuera muy fuerte a nivel nacional. Una vez en el gobierno, el desgaste de la gestión hizo que la aceptación del partido fuera disminuyendo, esto generó efectos en la participación del partido en las siguientes elecciones. En ese sentido, podemos observar que AP dejó de postular en una gran cantidad de provincias en 1986 y 1989, dentro de esos lugares con ausencia de candidatos se encuentran Yungay y Satipo. Pasados estos procesos electorales, AP volvería a aparecer en Yungay; mientras que en Satipo su ausencia se mantendría.

Como podemos observar en el Gráfico 6, en las elecciones municipales de 1980 y 1983 en Satipo, Acción Popular obtuvo una media alta de 42\%, pero después desapareció del espectro político por muchos años; mientras que en Yungay, Acción Popular tuvo una media de 21\% para cuatro procesos electorales. Estos resultados y la vuelta al espectro político de AP en Yungay, nos hacen pensar en un mejor desempeño del partido en esta provincia, un desempeño que ha incluido militantes, que hasta ahora persisten y recuerdan algunos hitos del partido en la ciudad, como lo manifestado por el exalcalde Dueñas:

Acción Popular ha sido un partido muy organizado, tuvimos como figura a Fernando Belaúnde Terry, él ha estado en esta zona, él ha dormido y comido acá [...] Abancay ha sido su bastión, somos bastantes acción populistas en la región (M. Dueñas, comunicación personal, 09 de agosto de 2015).

\section{Gráfico 6. Resultados electorales (1980-1995) para Acción Popular}

- Satipo

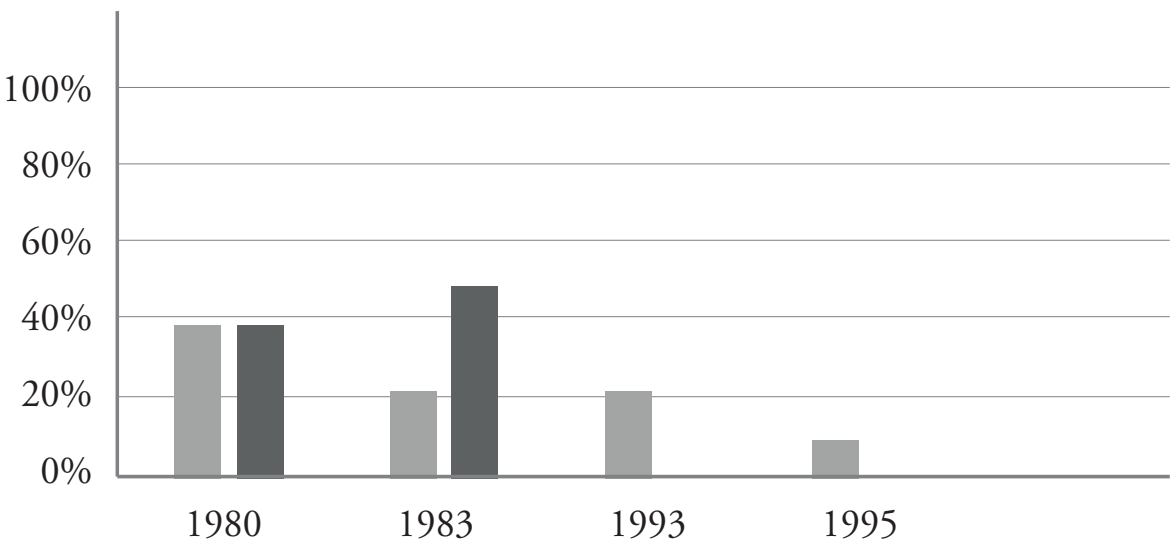


Después de las elecciones de 1995, AP ha participado en Yungay por tres procesos más $(2002,2010$ y 2014) y sus resultados no han superado el $10 \%$. En la ciudad de Satipo ha participado dos veces más en 1998 y 2002, también con resultados adversos que no superan el $10 \%$. Pero a diferencia de lo suscitado en esta ciudad, en Yungay han seguido participando dos candidatos del partido, Marcos Dueñas y Francisco Ávila; mientras que en Satipo los candidatos, Marino Zúniga y Jeremías Mercado, fueron invitados a postular con el partido. De esta forma, observamos que la presencia que pudo tener AP y las bases que pudo formar, han dejado legado en sus antiguos militantes para que estos prosigan con una vida política actualmente.

\section{Izquierda Unida}

El tercer partido a analizar es Izquierda Unida (IU), este movimiento nacional tuvo una fuerte presencia en todo el territorio nacional durante la década de 1980, desapareciendo para la de 1990. En Yungay, IU obtuvo un 21\% para cuatro procesos electorales; mientras que en Satipo obtuvo un $24 \%$ como promedio para tres de cuatro procesos electorales, en los cuales participó durante la década de 1980. Si bien para Izquierda Unida no se puede hablar de una diferencia tan fuerte como en los otros dos partidos descritos líneas arriba, sí es resaltante observar que en Yungay esta media fue más sostenida, ya que IU participó en una elección más, obteniendo muy buenos resultados, mientras que en Satipo solo obtuvo dos buenos promedios en 1983 y 1986, que no fueron sostenidos, e IU dejó de participar en la elección de 1989, como se puede observar en el Gráfico 7.

Gráfico 7. Resultados electorales (1980-1989) para Izquierda Unida

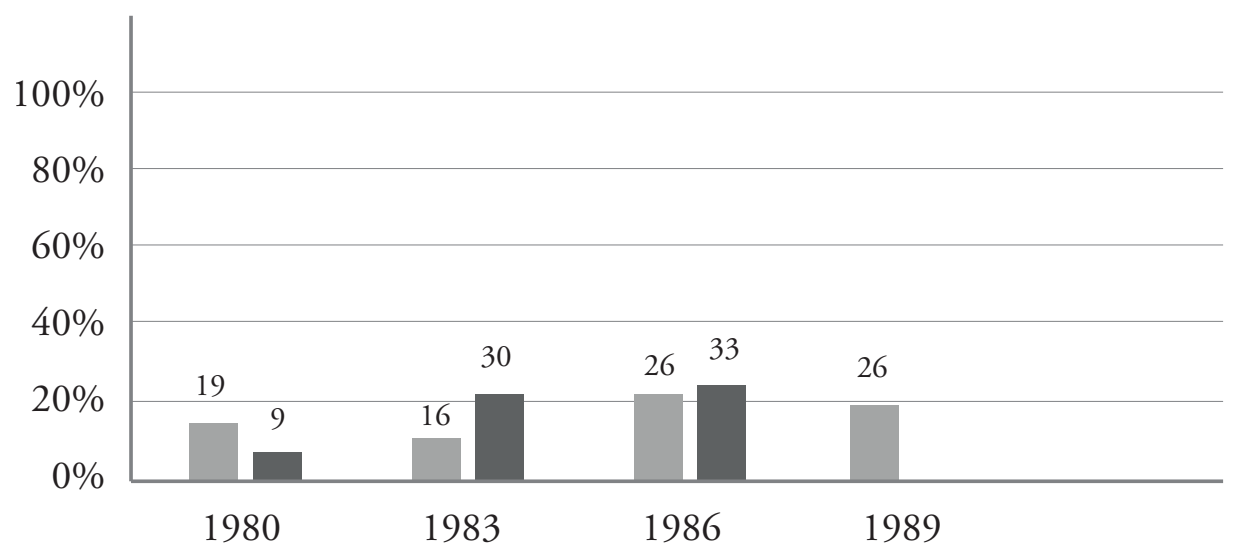


Pasado 1989, Izquierda Unida dejó de participar en las elecciones provinciales, ya que desapareció a inicios de la década de 1990. Si bien hoy en día solo podemos observar a Timoteo Giraldo Carrión como un candidato que persiste y fue formado en las filas de IU, se sabe de la presencia que tuvieron en la provincia, como lo declara Hernán Gómez, dirigente del Partido Popular Cristiano en la provincia y poblador yungaíno desde 1961:

La izquierda siempre ha estado acá [en Yungay], algunos de los profesores del pedagógico son militantes de Patria Roja y otros grupos de izquierda... En la década de los ochenta su presencia era mayor, dominaban el pedagógico y desde ahí hacían política en la provincia... sus antiguos dirigentes ya no están, he escuchado de ellos en Huaraz, creo que están haciendo política por allá (H. Gómez, comunicación personal, 07 de agosto de 2015).

De esta forma, podemos observar que si bien Izquierda Unida no tiene la misma presencia que los otros dos partidos nacionales en Yungay y Satipo, su presencia en la década de 1980 ha sido importante para el desarrollo político de las provincias, cuestión que podremos observar de manera más clara en algunos casos que presentaremos más adelante.

\section{Partido Popular Cristiano}

Finalmente, observamos el caso del Partido Popular Cristiano (PPC). La presencia de este partido fue más dispersa y volátil que la de los otros partidos en ambas provincias. Podemos observar que en Yungay obtuvo una media de participación de 16\%, mientras que en Satipo obtuvo un promedio de 27\%. Pero debemos resaltar algunos puntos respecto a estos datos, el primero es observar la cifra obtenida en 1989 en Satipo por el PPC, esta cifra fue bastante contextual ya que la cifra le corresponde al Frente Democrático (Fredemo), la alianza electoral realizada con el Movimiento Libertad para las elecciones de 1990; esta cifra puede reflejar la volatilidad del electorado respecto a los partidos políticos, ya que el PPC en 1983 y 1986 no logró pasar el 10\%. Por otro lado, en Yungay las cifras del PPC fueron más sostenidas, su máxima votación fue también con el Fredemo, pero esta dispersión no es comparable con lo ocurrido en Satipo, como podemos observar en el Gráfico 8.

A diferencia de los dos primeros partidos y de Izquierda Unida, la presencia del PPC fue poca en ambas provincias después de la elección de 1993. En Yungay volvieron a participar dos veces a la alcaldía provincial sin mayor éxito; mientras que en Satipo participaron una vez más en 2002 y lograron hacerse de la alcaldía con la candidata María Quevedo, pero al igual que en el caso de Acción Popular, sin mayor vínculo con el partido, sino en búsqueda de una marca partidaria que le permita participar. 
Gráfico 8. Resultados electorales (1980-1993) para el PPC

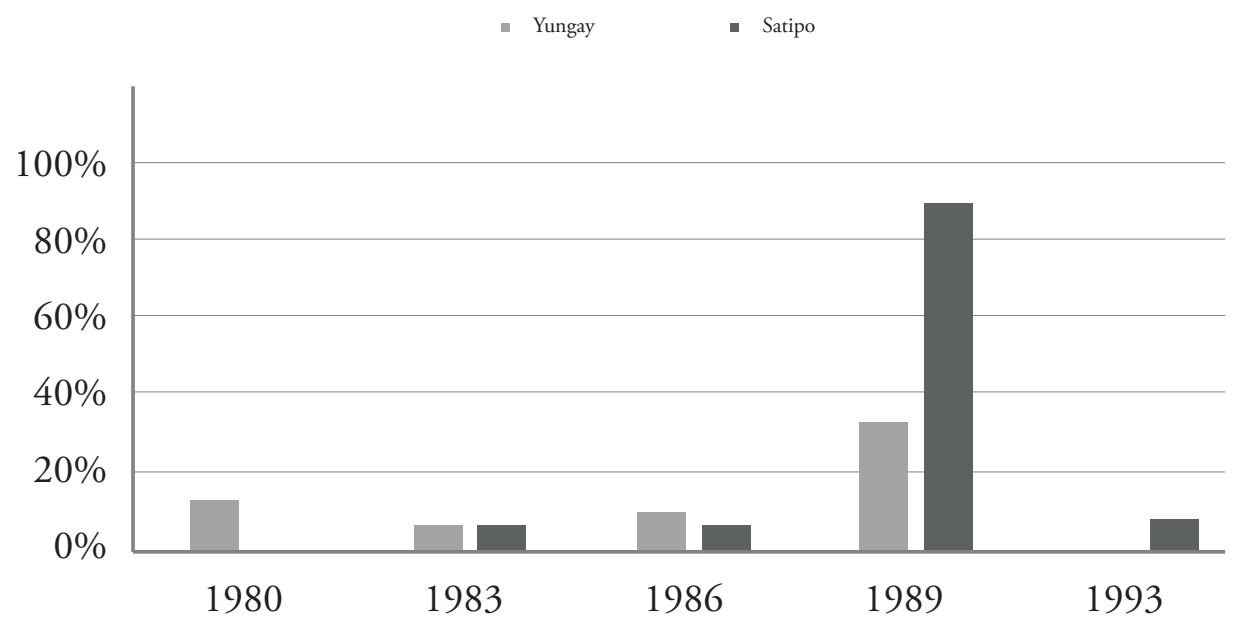

Fuente: JNE-Infogob. Elaboración propia.

Esta desvinculación que tiene el PPC a nivel subnacional fuera de Lima, ha hecho que muchos de sus antiguos militantes terminen marcando distancias de la política local pero no de la política en general, como lo manifiesta Hernán Gómez:

Ahora somos pocos los ppcistas que vivimos acá (en Yungay)... nosotros nos reunimos para ir a las plenarias nacionales, ahí donde se toman las decisiones fuertes... Hasta acá ha llegado Lourdes Flores para el 2001 y 2006, nosotros hemos puesto de nuestra plata para armar todo, escenario, parlantes, propagandas y esas cosas (H. Gómez, comunicación personal, 7 de agosto de 2015).

En ese sentido, observamos que la presencia de un partido como el PPC ha sido disminuida en la provincia de Yungay, en parte por el centralismo limeño del partido y por el desinterés de sus dirigentes por seguir participando en los procesos locales. Actualmente, no se encuentran registros de exmilitantes que postulan con otros movimientos o partidos, pero sí se sabe que tienen una pequeña maquinaria política en la provincia, que está integrada por militantes y da soporte al partido en los procesos nacionales. Además, y dependiendo de la ambición política de algunos de sus integrantes, tiene la posibilidad de desprenderse del partido y poder participar en cualquier otra lista en política.

De esta forma, podemos ver que esta variable es relevante para la construcción de carreras políticas a nivel subnacional, ya que el grado de penetración que cada uno de los cuatro partidos tuvo en la provincia en la década de 1980 
y principios de la de 1990, ha generado que una parte de las personas que componen el espectro de políticos con carreras, provengan de estas filas y se encuentren haciendo política constantemente, como se observa en el caso del APRA y Acción Popular en Yungay, y en menor medida en el caso de Izquierda Unida y el PPC. Ahora bien, esta variable se encuentra determinada por el trabajo que haya hecho cada uno de los partidos en cada provincia, ya que esta es distinta y podemos encontrar provincias donde la presencia de exmilitantes de un partido sea mayor que en otras.

\section{El autóctono versus el foráneo, la aceptación al migrante}

Esta tercera variable explicativa se centra en la clara diferencia entre los lugares de nacimiento de los políticos en nuestras provincias de estudio. Si observamos el caso de Yungay, veremos que la mayoría de políticos, durante las tres últimas elecciones, son naturales de la provincia, un $58 \%$ contra un $42 \%$. Mientras que en la ciudad de Satipo esta situación es distinta, la mayoría de políticos provienen de otras provincias, teniendo un total de $76 \%$ de foráneos contra un $24 \%$ de políticos originarios.

La explicación para este fenómeno nos lleva a desarrollar dos hipótesis, que pueden estar vinculadas. La primera aborda el tema del proceso de migración que ha ocurrido en cada ciudad y cómo esta ha transformado la política local. Mientras que la segunda tocará la formación de valores sociales y culturales en la población, que genera o degenera incentivos en los políticos para que persistan en la construcción de su carrera política.

El crecimiento poblacional de Satipo y Yungay ha sido muy distinto a lo largo de los ańos. Como se puede observar en el Gráfico 9, para el censo de 1981, Satipo y Yungay tenían una diferencia poblacional poco considerable; mientras que para el año 2007 esta brecha diferencial ha ido en gran aumento.

De esta forma, podemos inferir que una parte de la población que vive en Satipo es población migrante; además, es claro que esta tendencia de gran crecimiento que ha venido desarrollándose tiene su punto de inflexión más fuerte desde la década de 1990. Mientras que en Yungay el crecimiento ha sido muy poco, por no decir nulo; esto nos lleva a inferir sobre la poca migración que ha podido afectar a la ciudad.

En ese sentido, nos cuestionamos acerca de los factores que han permitido que existan estas diferencias en tasas de migración en ambas provincias y cómo esta se encuentra afectando la construcción de carreras políticas. 


\section{Gráfico 9. Crecimiento poblacional}

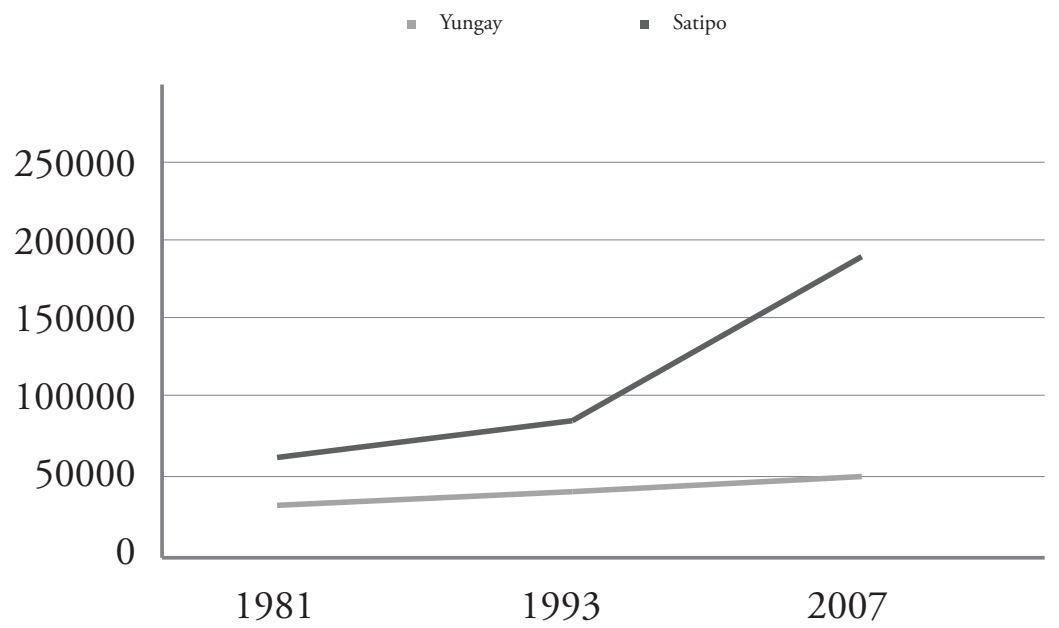

Fuente: INEI. Elaboración propia.

Un primer planteamiento nos lleva a observar la dinámica económica de las provincias, que es una causa natural de inmigración y emigración de un determinado territorio. En Satipo la principal actividad económica es la agricultura, que se centra en la siembra de café, cacao y diversos frutales. Esta actividad ha tenido un gran crecimiento en la ciudad - tal como lo informa el Banco Central de Reserva del Perú- durante 2011 y 2012, Satipo ha sido uno de los mayores productores del país en cuanto a café, naranja, piña y jengibre. El crecimiento de esta actividad, en un territorio amplio con grandes áreas de cultivo, ha llamado progresivamente a la inversión de capital privado tanto nacional como internacional en la ciudad. El efecto de esta dentro de la migración puede observarse de dos formas, una primera relacionada directamente con la actividad, como es el requerimiento de personal para su realización; y una segunda relacionada con el impacto en la dinámica económica y social de la ciudad, que produce el requerimiento de nuevos servicios que no han sido abastecidos por la población local.

Por su lado, la dinámica económica de Yungay enmarca tres actividades: agricultura, ganadería y minería. Las dos primeras son actividades que se han realizado a menor escala; mientras que la minería es una actividad que afecta en mayor porcentaje a la economía de la ciudad, sobre todo de la municipalidad, ya que el canon por minería que ha recibido esta durante 2012 ha sido de un poco más de 25 millones de soles, más del doble de lo que recibe la ciudad de Satipo. Esta actividad en la provincia se encuentra, principalmente, 
representada por el trabajo de la Compañía Minera Nueva California S.A., una empresa peruana que se dedica a la extracción de oro y plata en el distrito de Mancos; su producción minera no es muy abultada pero es importante para la economía local. En ese sentido, la capacidad productiva de esta empresa no ha generado grandes cambios sociales ni económicos en la ciudad, ya que el abastecimiento de mano de obra se encuentra cubierto por la población local.

Es así que observamos quizás el principal argumento en cuanto a la dinámica de migración en ambas provincias; ya que si bien existen otras causas importantes de migración, estas han afectado en menor medida el crecimiento poblacional de las provincias.

Por otro lado, y retomando la segunda explicación, que no excluye la primera, la tercera variable puede verse explicada por la fuerte presencia de valores sociales y culturales que rechazan que personas no naturales del lugar vayan a ocupar el cargo de alcaldía provincial, que es un cargo de representación popular.

En ese sentido, si observamos a los tres últimos alcaldes en ambas provincias, vemos que en Yungay dos de ellos son naturales de la provincia y el tercero, el actual alcalde, vive en la ciudad desde hace más de cuarenta años. A diferencia de Satipo, donde los tres últimos alcaldes elegidos han sido migrantes.

Esta variable, además, se puede ver reforzada con la manifestación de algunos de los políticos migrantes, que informan lo hostiles que son las campañas políticas contra ellos en Yungay y el discurso que usan muchos de sus contrincantes para referirse a su posición de migrantes. Como informa el candidato Segundo Jacome:

Es que acá en la ciudad de Yungay, existe el antihuaracinismo, ello se ha creado después del terremoto de 1970 y es que los yungaínos creen que Yungay no ha crecido por falta de apoyo de la provincia de Huaraz, y ellos piensan siempre que el apoyo que venía para Yungay se quedaba en Huaraz. Entonces existe esa especie de resentimiento, prácticamente, yo he sido candidato contra once, que mayormente eran de la ciudad de Yungay. Entonces, ellos, prácticamente, iniciaron el cargamontón y me hicieron una contracampaña de que yo era huaracino y de que si podía ganar las elecciones en Yungay me iba a llevar todo para Huaraz (S Jacome, comunicación personal, 07 de agosto de 2015).

En estas condiciones, muchos de los posibles políticos que no son naturales de Yungay limitan su participación para evitar esta situación, generando que los políticos nacidos en Yungay restrinjan la oferta de éxito en política para la provincia.

Esta situación es muy distinta en la ciudad de Satipo, donde los migrantes no tienen estos problemas para hacer política. Como ya se explicó líneas arriba, la mayoría de postulantes a la alcaldía han sido migrantes. 
En conclusión, como se ha podido observar, estas dos formas de explicar el fenómeno del autóctono versus el foráneo se encuentran íntimamente relacionadas, ya que la gran tasa de migración en Satipo es una de las causas de que exista una buena presencia de políticos, sean migrantes o no, y dado el cambio estructural que ha sufrido la ciudad, los satipeños no tienen mayores sentimientos de rechazo hacia el foráneo. Mientras que en Yungay esta dinámica se da de manera contraria, ya que dada la poca migración que ha existido, el sentimiento de rechazo hacia personas con poca permanencia en la ciudad no ha disminuido.

Ahora bien, ¿cómo afecta esto a las carreras políticas? Considero que puede afectar de dos maneras. En el caso de Satipo, donde existe una mayor aceptación al migrante como político, nos da la posibilidad de que algunos de los candidatos que han postulado una sola vez, que en muchos casos son migrantes, dejen de hacerlo porque no les genera mayores incentivos volver a postular y prefieren seguir sus actividades relacionadas a la provincia de manera normal. Por el lado de Yungay, la poca participación de migrantes abre la posibilidad a que antiguos políticos sigan tentando el poder constantemente, ya que la demanda política no se abre a nuevas personas.

Finalmente, quiero comentar sobre otras provincias, donde nuestras variables explicativas se están cumpliendo de manera similar a nuestros casos, y también observar algunas otras variables explicativas.

\section{Las carreras políticas en otras provincias}

A continuación observaremos de manera general los casos de Urubamba, El Dorado y Calca, tres provincias que se encuentran entre los primeros puestos de ciudades con mayor cantidad de políticos que han estado y están construyendo carreras políticas.

\section{Urubamba}

La provincia de Urubamba, ubicada en la región Cusco, es una de la ciudades con el promedio más alto de políticos que han construido carreras políticas, un $86 \%$. Al igual que la provincia de Yungay, en Urubamba se cumplen, parcialmente, los supuestos de la investigación. Primero, observamos que durante los tres últimos procesos electorales la oferta política de candidatos al sillón municipal estuvo compuesta por dieciocho personas. En este grupo de personas la distribución de los estudios profesionales se ha dado de la siguiente forma: ocho políticos provienen de las aulas de la Universidad Nacional San Antonio Abad del Cusco (UNSAAC), cinco políticos del Instituto Superior 
Público La Salle-Urubamba, tres personas sin registro educativo y dos personas de otras instituciones a nivel nacional. Si bien la UNSAAC no se encuentra en Urubamba, la distancia entre ambas es, aproximadamente, de una hora, por lo que muchos de los pobladores optan por acercarse a esta institución.

Por otro lado, y en referencia al tercer supuesto, encontramos que en este universo de políticos de Urubamba, quince han nacido en la provincia y solo existen tres políticos que provienen de otras provincias; además, ninguno de estos tres ha logrado ser elegido alcalde en las tres últimas contiendas electorales.

En cuanto a nuestro segundo supuesto, la presencia de los partidos políticos en las décadas de 1980 y 1990, podemos observar que si bien los partidos no han tenido desempeños homogéneos, incluso algunos han dejado de participar en algún proceso (Tabla 6). Partidos como Izquierda Unida han logrado obtener resultados más sostenidos, con un promedio de $38 \%$ para cuatro elecciones. Además, tres de los candidatos, entre ellos un exalcalde, declaran haber sido militantes de Izquierda Unida. El desempeńo del APRA y Acción Popular también es importante, aunque esta encuentra ciertos baches que están determinados por el contexto de la política nacional y su relación con el partido. De esta forma, observamos que cuatro de los candidatos, entre ellos el actual alcalde, han sido militantes apristas y acciopopulistas, dos y dos respectivamente, durante la década de 1990.

Tabla 6. Resultados electorales (1980-1993) en Urubamba

\begin{tabular}{|c|c|c|c|c|c|c|}
\hline Región & 1980 & 1983 & 1986 & 1989 & 1993 & Promedio \\
\hline Acción Popular & $45 \%$ & $25 \%$ & & $24 \%$ & $4 \%$ & $25 \%$ \\
\hline Izquierda Unida & & $48 \%$ & $39 \%$ & $50 \%$ & $15 \%$ & $38 \%$ \\
\hline APRA & $18 \%$ & $13 \%$ & $61 \%$ & $12 \%$ & $1 \%$ & $21 \%$ \\
\hline PPC & & $5 \%$ & & $14 \%$ & $5 \%$ & $8 \%$ \\
\hline
\end{tabular}

Fuente: JNE-Infogob. Elaboración propia.

En ese sentido, podemos decir que la presencia de los partidos ha sido relativamente fuerte en estas provincias y algunos de los rezagos de esos ańos tienen injerencia sobre la política local, a través de políticos que han iniciado la construcción de su carrera política desde esta década.

\section{El Dorado}

El Dorado es una provincia ubicada en el departamento de San Martín y su creación data del año 1992, anteriormente estuvo adherida a la provincia de 
Lamas. A comparación de otras provincias, es una de las más jóvenes, pero su tasa de candidatos con carreras políticas es la más alta del país.

La provincia cuenta con un universo de diez personas que han participado durante los tres últimos procesos electorales y observamos que cinco de los candidatos han realizado sus estudios en el Instituto Superior Pedagógico de Tarapoto; mientras que de los otros cinco, tres no cuentan con estudios superiores y dos realizaron estudios en otras instituciones locales. Asimismo, podemos observar que siete de los diez candidatos son personas que han nacido en la provincia de El Dorado.

Finalmente, y respecto a la presencia de los partidos políticos en la década de 1980, dado que la provincia se creó después del derrumbe del sistema de partidos, es complicado evaluar el desempeño de los mismos, aunque podemos observar los resultados de los partidos en la provincia de Lamas, a la cual estuvo adherida hasta 1992. Lo más resaltante son los resultados que obtuvo el Partido Aprista Peruano, un 50\% de los votos en 1980, un $45 \%$ en 1983 , un $74 \%$ en 1986, un $45,5 \%$ en 1989 y un $33 \%$ en 1993 , lo que nos hace pensar en una fuerte presencia del APRA y su militancia, ya que la poca aceptación con la que termina el primer gobierno aprista no hizo que no se obtuvieran buenos resultados, aunque estos se redujeron. En ese sentido, el castigo al partido se dio pero se ha mantenido un respaldo que refiere a la formación de militantes y lealtad al partido.

\section{Calca}

Un caso similar al de Urubamba es el de su provincia colindante, Calca, en el Cusco, cuyo promedio de candidatos con carreras políticas, de $95 \%$, es parecido, y las variables explicativas planteadas se van cumpliendo. La presencia de los partidos en la década de 1980 es similar, con una Izquierda Unida con resultados más constantes, pero una presencia importante de Acción Popular y el Partido Aprista Peruano. Asimismo, la presencia de la UNSAAC y del Instituto Pedagógico de Urubamba hace que diez de los trece aspirantes al sillón municipal hayan pasado por sus aulas. Finalmente, la presencia de migrantes en política también es reducida, cuatro de trece han nacido en otras provincias, lo que nos hace pensar en la poca tasa de migración que hay en la provincia.

De esta forma, hemos observado mediante el estudio de tres casos más, ubicados en los niveles altos del índice de construcción de carreras políticas, que nuestros tres supuestos se están cumpliendo y que esta explicación no solo vincula a dos provincias, sino que se puede observar en más casos. 


\section{Conclusiones}

Las conclusiones que la investigación ha desarrollado pueden ser categorizadas en tres grupos.

En un primer grupo hemos observado la presencia de carreras políticas a nivel local en el Perú y cómo esta se configura en la política nacional; lo que genera efectos en la oferta política local y la volatilidad.

Un segundo grupo de conclusiones está vinculada a nuestra pregunta de investigación: ¿qué factores han permitido la construcción de carreras políticas a nivel subnacional?, y las explicaciones que se han encontrado mediante el estudio comparado.

Finalmente, una tercera parte de las conclusiones busca generar nuevos cuestionamientos al funcionamiento de la política y a una agenda de investigación que está siendo poco desarrollada.

De estas forma, hemos podido observar que los políticos que han construido sus carreras políticas a nivel subnacional en el Perú no son pocos, por el contrario, se demuestra de manera empírica que poco más del $70 \%$ de candidatos a las alcaldías provinciales, en promedio, han tenido alguna experiencia de participación electoral a cargos de elección previa. Esto quiere decir que de diez personas que postulan a la alcaldía, solo tres son nuevas en política, outsiders, y los otros siete son personajes ya conocidos en la provincia que vienen haciendo trabajo político desde mucho antes. Esta dinámica de la política local es clave para entender algunos aspectos del sistema de partidos y los partidos políticos, ya que si bien mucho del sentido común asocia al Perú como un país con una democracia en construcción y con una volatilidad partidaria alta, este argumento no es el mismo si se estudia la trayectoria política de las personas que encabezan las listas partidarias. En ese sentido, podemos decir que si bien los partidos políticos son muy débiles a nivel subnacional, la presencia de candidatos que han construido carreras políticas en sus localidades están copando estos espacios de representación mediante mecanismos que les brinden mayores facilidades, lo que Zavaleta (2014) reconoce como un sustituto partidario para formar coaliciones de independientes.

Dicho esto, el trabajo demostró, mediante un estudio comparado, que las condiciones han sido necesarias para que existan políticos que construyen carreras políticas y que normalmente limitan la oferta electoral. En ese sentido, se reconoció tres variables explicativas que generaron distinción entre ambos casos, la primera es la presencia de instituciones que generan el incremento por hacer política de los ciudadanos; así como la influencia que llegan a tener sobre 
el desarrollo de la ciudad. La segunda variable explicativa es el arraigo que tuvo el sistema de partidos en la década de 1980, lo que generó que muchos políticos hayan sido formados dentro de partidos, con el rol de militantes, por lo que su presencia en política es más continua; ahora bien, esta variable se encuentra determinada por los distintos grados de presencia que tuvieron los partidos en cada provincia. Finalmente, nuestra tercera variable explicativa es la aceptación del migrante en la política local, esta variable observa el grado de migración que ha tenido la provincia y cómo esta ha transformado la política local, lo que es vinculado a la aceptación que el migrante tiene en la sociedad para hacer política, ya que como se observó, algunos de los desincentivos para seguir haciendo política provienen de valores culturales de rechazo a los migrantes que quieren hacer política.

Las explicaciones que hemos mostrado para la formación de carreras políticas dan algunas pistas para explicar este fenómeno, pero es muy probable que existan otras variables explicativas que deben ser tomadas en cuenta para futuros estudios. Además, si bien existe un campo de la ciencia política que es poco estudiado en el país, como son las carreras políticas y la ambición política, su estudio a mayor profundidad podría dar luces de un tema esencial para la política nacional, como es la formación de élites políticas locales. Ya que si bien el concepto de este es más amplio al de carrera política, es claro que para ser una persona con liderazgo político, el haber construido una carrera política en su localidad es por lo menos un requisito para ser parte de esta élite, cuya capacidad de proponer y poner en práctica ciertas políticas puede cambiar el futuro de su ciudad (Dietz, 2003, p. 11).

Finalmente, observamos una agenda mayor que se abre a partir de la investigación. Primero, es necesario realizar una exploración más sistemática de las provincias y del mundo de los municipios provinciales, este tipo de estudio ayudaría a saber cómo se enlaza el fenómeno de políticos con carreras con el funcionamiento de los municipios provinciales. Asimismo, queda pendiente saber lo que ocurre con las personas que construyen carreras políticas en otros espacios - como es el caso de las elecciones congresales, regionales o distritales-, y observar el tipo de implicancias que puede traer el contar con políticos que han construido y están construyendo carreras políticas en un país con partidos nacionales tan débiles como el Perú. 


\section{BibLIOGRAFÍA}

Aragón, J. e Incio, J. (2014). La reelección de autoridades regionales y municipales en el Perú, 2006-2014. Revista Argumentos, 8(5), S/P. Recuperado de: http://revistaargumentos.iep.org.pe/ articulos/la-reeleccion-de-autoridades-regionales-y-municipales-en-el-peru-2006-2014/

Aragón, J. e Incio, J. (2015). La medición de la volatilidad electoral en sistemas de partidos escasamente institucionalizados. Análisis del caso peruano. En E. Dargent, y M. Tanaka (eds.), ¿Qué implica hacer ciencia política desde el sur y desde el norte? (pp. 39-64). Lima, Perú: Escuela de Gobierno PUCP.

Barrantes, R.; Cuenca, R. y Morel, J. (2012). Las posibilidades del desarrollo inclusivo, dos historias regionales. Lima, Perú: Instituto de Estudios Peruanos.

Barrenechea, R. (2010). Elecciones regionales 2010: Liderazgos políticos en ciernes. Revista Argumentos, 5(5), S/P. Recuperado de: http://revistaargumentos.iep.org.pe/articulos/ elecciones-regionales-2010-liderazgos-politicos-en-ciernes/

Dietz, A. (2003). Élites y poderes locales: sociedades regionales ante la descentralización, los casos de Puno y Ayacucho. Lima, Perú: Ser \& DFID.

Levitsky, S. y Cameron, M. (2003). Democracy whitout Parties? Political Parties and Regime Change in Fujimori's Peru. Latin American Politics and Society, 45(3), 1-33. doi: 10.2307/3177157

Meléndez, C. (2012). Partidos inesperados. La institucionalización del sistema de partidos en un escenario de post colapso partidario. Perú 2001-2011. Lima, Perú: Fundación Friedrich Ebert.

Meléndez, C. y Vera, S. (2006). Si todos perdieron, ¿quién ganó? Los movimientos regionales en las elecciones de noviembre del 2006. Revista Argumentos, 1(4), 2-7.

Pedersen, M. (1979). The dynamics of West European party systems: Changing patterns of electoral volatility. European Journal of Political Research, (7), 1-26. doi: 10.1111/j.1475-6765.1979. tb01267.x

Pereira, V. (1992). Legitimación y socialización política en Venezuela. Cuestiones Políticas, 13, 31-56. Pratt, H. (1984). Diccionario de Sociología. México D.F, México: Fondo de Cultura Económica.

Rodríguez, M. A. y Coronel, O. (eds.) (2011). Perú debate, el nuevo poder en la regiones. Lima, Perú: Pontificia Universidad Católica del Perú, Facultad de Ciencias Sociales.

Tanaka, M. (1998). Los espejismos de la democracia. El colapso del sistema de partidos en el Perú. Lima, Perú: Instituto de Estudios Peruanos.

Tanaka, M. (2005). La democracia sin partidos. Perú 2000-2005: los problemas de representación y las propuestas de reforma política. Lima, Perú: Instituto de Estudios Peruanos.

Tanaka, M. y Meléndez, C. (2013). The future of Peru`s Brokered Democracy. En D. Abante y L. Diamond (Eds.), Political Clientelism, Social Policy, and the Quality of Democracy (pp. 65-87). Baltimore, MD: The Johns Hopkins University Press.

Vera, S. (2010). Radiografía a la política en las regiones: tendencias a partir de la evidencia de tres procesos electorales. Revista Argumentos, (5) S/N. Recuperado de: http://revistaargumentos.iep. org.pe/articulos/radiografia-a-la-politica-en-las-regiones-tendencias-a-partir-de-la-evidenciade-tres-procesos-electorales/

Vilca, P. (2014). Los persistentes de la politica: redes politicas en el altiplano puneño. Tesis de maestría. Pontificia Universidad Católica del Perú, Lima.

Zavaleta, M. (2014). Coaliciones de independientes, las reglas no escritas de la política en el Perú. Lima, Perú: Instituto de Estudios Peruanos. 